\title{
Design and Simulation of Liftable Crawler Chassis for Combine Harvester
}

\author{
Jing Bo ${ }^{1}$, Xu Lizhang ${ }^{2}$ \\ Key Laboratory of Modern Agricultural Equipment's and Technology, Ministry of Education, Jiangsu \\ University, Zhenjiang, China \\ jb18851401901@163.com¹, justxlz@ujs.edu.cn²
}

\begin{abstract}
Aiming at the needs of field operations in different deep mud, a liftable crawler chassis based on the connecting rod arm mechanism was designed, including the chassis upper frame, lifting mechanism, hydraulic cylinder, limit mechanism, left and right walking system. In the ADAMS software, a virtual prototype model of the lifting and lowering chassis is established. The angle variation of the frame on the chassis relative to the ground and the angular velocity and acceleration of each lifting rod were simulated and analyzed. These rules met the chassis lifting adjustment requirements during the harvester operation.
\end{abstract}

Keywords: Lifting chassis; Modeling; ADAMS simulation; Kinematics

Language: English

Date of Publication: 2018-27-10

ISSN: 2349-0837

Volume: 08 Issue: 01

Journal: JOURNAL OF ADVANCES IN AGRICULTURE

Website: https://cirworld.com

This work is licensed under a Creative Commons Attribution 4.0 International License.

How to Cite: Bo, J., \& Lizhang, X. (2018). Design and Simulation of Liftable Crawler Chassis for Combine Harvester.JOURNAL OF ADVANCES IN AGRICULTURE, 8(1), 1476-1487. Retrieved from https://cirworld.com/index.php/jaa/article/view/7809 


\section{Introduction}

China is the world's largest rice producer and consumer, with paddy field and paddy production accounting for $21 \%$ and $35 \%$ of the world, respectively [1]. The total area of rice planted in the middle and lower reaches of the Yangtze River accounts for two-thirds of the total rice planting area in China, and these rice fields are characterized by small overall area, scattered, many ridges and serious silt [2][3]. In the combined harvesting operation of rice, high-humidity land is difficult to harvest. The main reason is that the mud feet are deep, generally $30-40 \mathrm{~cm}$. The gearbox casing and even the chassis of the crawler combine harvester are trapped in the field, resulting in large forward resistance, high power consumption, low operating efficiency and low work quality [4]. The combine harvester is located at a shallower and less deeply paved road, and when walking on a dry road, the center of gravity of the chassis should be low. When the harvester enters the mud foot depth greater than $25 \mathrm{~cm}$ paddy field operation, the chassis height should be adjusted in time to keep the chassis above the sludge, and the whole combine harvester maintains good field possibility and reduces power consumption. Therefore, the study of the liftable crawler chassis device is the key to solving such problems.

At present, Japanese companies produce combine harvesters with adjustable ground clearance. For example, the Kubota $888 \mathrm{GM}$ semi-feed combine harvester is equipped with a chassis automatic lifting system. The paddy field has the best possibility and can be used in mud feet not more than $45 \mathrm{~cm}$ deep. Block harvesting is the most suitable model for high-humid muddy plots [4]. The AL QUATTRO EVO wheeled wheat harvester produced by LAVERDA of Italy has horizontal and vertical leveling functions, which can be adapted to the hillside and other slopes by improving the structure of the harvester chassis [5]. Newlin designed a shear fork table lift that includes a chassis, a table, a scissor lift mechanism, and a retractable mechanical drive [6]. Heckert and Pfleghaar designed a device that uses a special traction mechanism to control the change in the center angle of the two intersecting scissor arms to achieve the lifting motion [7]. Rémi Figueredo et al. performed a kinematic analysis of the forklift mechanism of the dump truck and optimized the hydraulic cylinder position and mechanical structure using genetic algorithms [8]. Chinese scholars have done a lot of research on height lifting and adjusting horizontal devices. Wang Xiaolong et al. designed an orchard lifting platform leveling device that can adapt to the $0-15^{\circ}$ leveling requirements and conducted experiments. The working platform is driven by a hydraulic motor and the test leveling error is between $\pm 1^{\circ}$ [9]. In addition, the all-terrain contoured walking power chassis [10] is also an important direction for chassis research. The multidegree-of-freedom contouring walking device can improve the terrain adaptability and possibility of the chassis [11]. For example, Wang Decheng and Zhao Jianzhu designed an agricultural profiled crawler-type power chassis and carried out theoretical analysis and experimental verification of the track profile chassis [12]. However, the above chassis has its specific use occasions, and cannot fully meet the requirements of the carrying capacity and adjustment range of the lifting device in the paddy combine harvester in the paddy field. Therefore, it is necessary to redesign the lifting and lowering device based on the crawler combine harvester and carry out targeted design calculations and simulation analysis.

In the ADAMS multi-body dynamics study, the established 3D model is imported into the software, and the dynamic characteristics of the working mechanism are analyzed by given mechanism parameters [13] [14]. Imanish and others obtained some deformation characteristics of the working device through the dynamic simulation of the working process of the excavator, and also verified the superiority of the dynamic simulation analysis method in the structural design of the excavator [15]. In this paper, the form of the hydraulic cylinder driving the arm between the crawler chassis and the upper frame of the combine harvester is realized, and the attitude of the frame on the chassis relative to the traveling wheel train is realized. Realize the adjustment of the height of the chassis from the ground and ensure that the chassis maintains a certain level of accuracy when the ground is tilted, ensuring that the harvesting operation of the combine harvester is always stable and efficient. The kinematics simulation of the designed model is carried out by using ADAMS software to obtain the movement of the lifting mechanism in different attitudes of the chassis, and verify the correctness of the theoretical analysis model, which provides a basis for the next step to check the strength of the lifting mechanism. 2 Lift adjustable tracked chassis mechanism design The crawler combine harvester chassis mainly 
consists of a chassis upper frame, a lifting mechanism, an engine, a cab, and a left and right walking system. As shown in Figure 1.

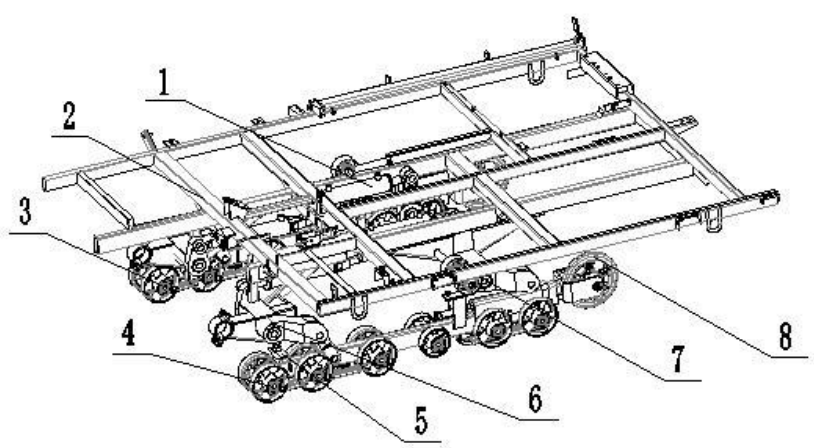

Fig. 1Chassis structure schematic (1. Hydraulic cylinder 2. Chassis rack 3. Right walking system 4. Left walking system 5 . Limiting mechanism 6 . Front lifting mechanism 7. Rear lifting mechanism 8 . Tension wheel)

The chassis device eliminates the design of the traditional figure-shaped beam, strengthens the structure of the chassis frame, and adds a lifting mechanism between the traveling beam and the frame. It can also adapt to the situation where the left and right height differences appear on the ground. The main technical parameters of the main parameters of the lifting chassis are shown in Table 1.

Tab.1 Lifting chassis technical parameters

\begin{tabular}{|c|c|}
\hline Menu & Value \\
\hline $\begin{array}{l}\text { Chassis load } \\
\text { bearing } / \mathrm{kg}\end{array}$ & 5500 \\
\hline $\begin{array}{l}\text { Chassis height } \\
\text { range/mm }\end{array}$ & $\begin{array}{l}450 \sim \\
600\end{array}$ \\
\hline $\begin{array}{l}\text { Lateral height } \\
\text { difference } / \mathrm{mm}\end{array}$ & 200 \\
\hline $\begin{array}{l}\text { Longitudinal } \\
\text { angle/ }\left(^{\circ}\right)\end{array}$ & \pm 5 \\
\hline
\end{tabular}

\subsection{Lift mechanism design}

Through detailed research on high-adjustment institutions at home and abroad, a four-point adjustment type lifting mechanism is proposed. The lifting mechanism is divided into a left front lifting mechanism, a right front lifting mechanism, a left rear lifting mechanism, and a right rear lifting mechanism.

As shown in c, $d$ in Figure 2. In the front lifting mechanism, the distance between the two ends of the lower arm is $200 \mathrm{~mm}$; the distance between the two holes of the upper arm is $100 \mathrm{~mm}$. Both ends of the shaft of the nested spline. Ensure that there is no relative displacement between the upper and lower arms and the shaft. In order to avoid the interference between the lifting mechanisms and reduce the distortion of the chassis frame, a special arm connecting member is added between the front lower arm and the traveling beam. The center distance of the shaft holes at both ends of the arm joint is $150 \mathrm{~mm}$. In the rear lifting mechanism, the 
distance between the two link holes of the lower arm is $200 \mathrm{~mm}$; the distance between the two holes of the upper arm is $195 \mathrm{~mm}$. Both ends of the shaft of the nested spline. And the upper and lower arms maintain a fixed angle, and there is no relative movement with the spline shaft. The hinge holes are $30 \mathrm{~mm}$ in diameter.
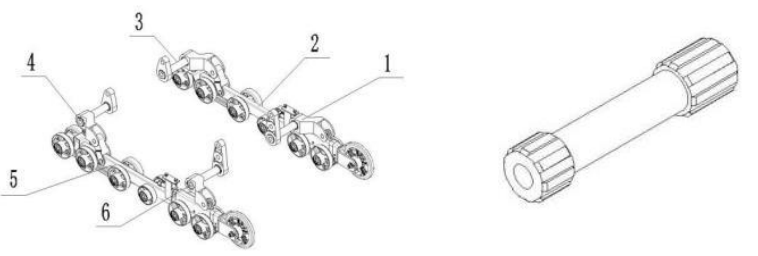
a. Lifting
b. Spline shaft
mechanism

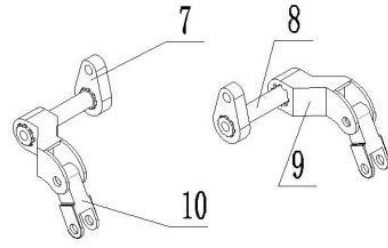

c. Front lifting mechanism

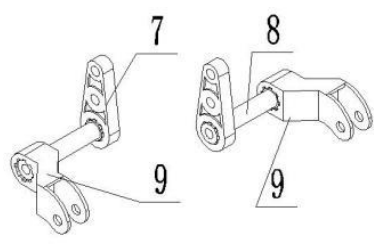

d. Rear lifting mechanism

Fig. 2 Reciprocating vertical cutter harvesting diagram (1. Right rear lifting mechanism 2. Right walking system 3. Right front lifting mechanism 4. Left front lifting mechanism 5 . Left walking system 6 . Left rear lift system 7. Upper arm 8. Spline shaft 9. Lower arm 10. Boom connector)

\subsection{Limit mechanism design}

The chassis is the main load-bearing component, and the chassis always has a downward trend during the lifting process. This requires the design of a special limit mechanism to prevent the chassis from being lower than the adjusted minimum position, to avoid the chassis and the wheel train being squeezed, resulting in difficulty in walking and deformation and damage of the lifting mechanism. Structure as shown in Figure 3.

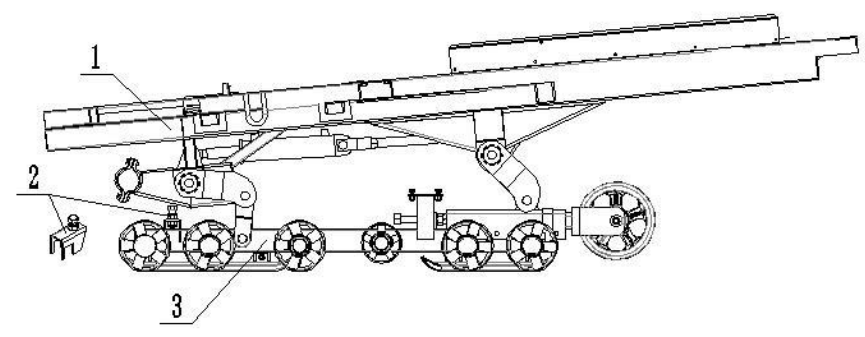

Fig.3 Schematic diagram of the limit mechanism

\section{(1. Chassis rack 2. Limiting mechanism 3. Walking system)}

There is one on the left side and the right side of the limit mechanism. The bent plate is welded to the walking beam, and the steel plate has bolts to limit the minimum adjustment position of the adjusting mechanism. 


\subsection{Analysis of the principle of lifting and leveling chassis mechanism}

The degree of freedom calculation is performed on the lifting chassis, and the feasibility of the mechanism is verified from the degree of freedom.

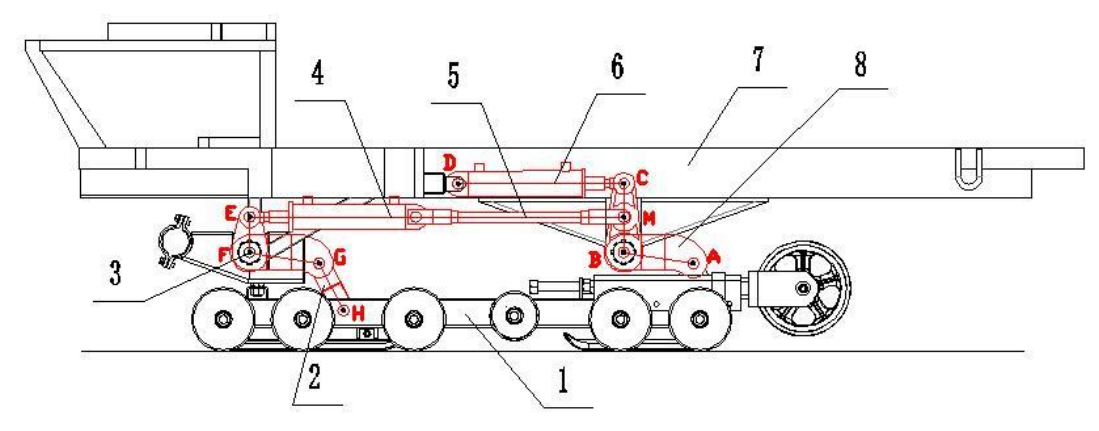

Fig.4 Freedom degree calculation diagram (1. Walking system 2. Rotating arm connection 3. Front rotating arm 4. Front hydraulic cylinder 5. Front hydraulic cylinder connection 6 . Rear hydraulic cylinder 7. Chassis rack 8 . Rear rotating arm;)

In Fig. 4, the arm $A B C$ is a rear lifting mechanism, and the side view is L-shaped, wherein the arms $A B$ and $B C$ are fixed at an angle of 99 degrees. $L C D$ is the actual length of the rear hydraulic cylinder, variable length. The arm EFG is a front lifting mechanism and is also L-shaped. The EF section and the FG section are fixed at 99 degree angle. EM stands for the front hydraulic cylinder and the intermediate link. It can be considered as a straight, straight rod without deflection. The length varies with the change of the front hydraulic cylinder. Equivalent rod EM and CBA hinged at $\mathrm{M}$ point. GH is a swing arm connecting piece that connects the front lifting mechanism and the walking beam, and its supporting function. As shown in the figure, there are two sets of structures, which are arranged symmetrically between the frame and the walking system on the chassis to adjust the attitude of the chassis.

Taking the one-side lifting mechanism as an example, the walking system is fixed, and the two points of $A$ and $\mathrm{G}$ are not moving. The two movable members of the hydraulic cylinder and the piston rod form a moving pair, and the movable member works 8 pieces, 9 rotating pairs, and two moving pairs. The degree of freedom is calculated as follows [16].

$$
F=\sum_{i=1}^{p} f_{i}-\sum_{i=1}^{L} \lambda_{i}-f_{a}-f_{0}-\lambda_{0}
$$

Where: $f_{i}$ is the degree of freedom of the $i$ th motion pair, $\mathrm{P}$ is the number of motion pairs, $\lambda_{i}$ is the number of closed constraints in the closed loop, $\mathrm{L}$ is the number of closed loops, $f_{a}$ is the local degree of freedom, $f_{0}$ is the negative degree of freedom, and $\lambda_{0}$ is the virtual constraint.

Calculated by the formula of degrees of freedom:

$$
F=3 \times 8-2 \times 11-0=2
$$

The four hydraulic cylinders are symmetrically arranged on the left and right sides, and the one-side lifting mechanism is connected front and rear, and the left and right sides are independently moved to jointly determine the tilt angle posture of the chassis. There is a one-to-one correspondence between each hydraulic cylinder and the chassis and the ground inclination angle. The adjustment of the chassis attitude can be realized by actively adjusting the expansion and contraction of the hydraulic rod piston rod. It is not difficult to 
see from the calculation process that the stroke of the cylinder determines the range of chassis attitude adjustment. In this paper, the ground is regarded as horizontal, and the limit of the angle between the lifting chassis and the ground is the maximum angle at which the chassis device can adapt to the terrain.

\subsection{Limit mechanism design}

The hydraulic cylinder acts as a drive element that converts hydraulic energy into mechanical energy [17]. Among them, the selected hydraulic cylinder uses earring connection type, the front hydraulic cylinder stroke is $400 \mathrm{~mm}$, and the rear hydraulic cylinder is $200 \mathrm{~mm}$. The hydraulic cylinder parameters are shown in Table 2 .

\section{Tab.2 Hydraulic cylinder main parameters}

\begin{tabular}{cc}
\hline Menu & Value \\
\hline $\begin{array}{c}\text { Model } \\
\text { Working } \\
\text { pressure/MPa } \\
\text { Highest } \\
\text { pressure/MPa } \\
\text { Maximum } \\
\text { speed/ (m/s) } \\
\begin{array}{c}\text { Cylinder } \\
\text { diameter/mm } \\
\text { Piston rod }\end{array} \\
\text { diameter/mm } \\
\text { Stroke/mm }\end{array}$ 20 & 0.5 \\
& 35 \\
\hline
\end{tabular}

\section{ADAMS Simulation}

\subsection{Create a virtual prototype}

\subsubsection{Import model}

Divide the model in Solidworks into several active components, copy the same number of final assemblies, delete each part except one active component, and save each component independently in Parasolid format. Import the ADAMS environment separately and set the 'File Type' of the model to ASCII format during the import process. The imported file is converted to a Part, not a Model [18]. As shown in Figure 5. 


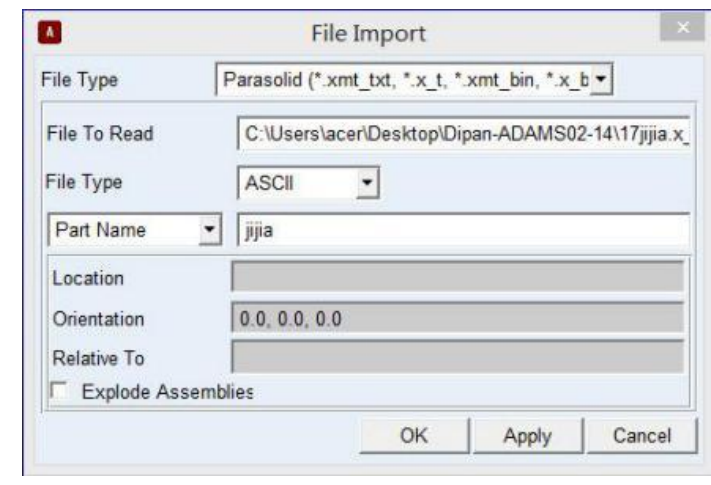

Fig.5 Import model

\subsubsection{Add constraint}

The positional relationship between the components imported into ADAMS is the same as in Solidworks, but the relationship between them does not exist, and the constraints need to be added again. First fix the walking system to the ground, with the fixed pair. Each lifting mechanism and all end points of the hydraulic cylinder are hinged, and a rotating pair should be added. The cylinder between the cylinder and the piston rod is the mobile pair. The model has a total of 18 rotating pairs, 4 moving pairs, and 2 fixed pairs.

\subsubsection{Add quality attributes}

Select the component, select modify in the shortcut menu of the right mouse button, and the interface shown in Figure 6 appears. Choose to define the quality according to the material type of the geometry machine, select the steel type, determine the density and elastic modulus, Poisson's ratio, and automatically calculate the centroid and moment of inertia.
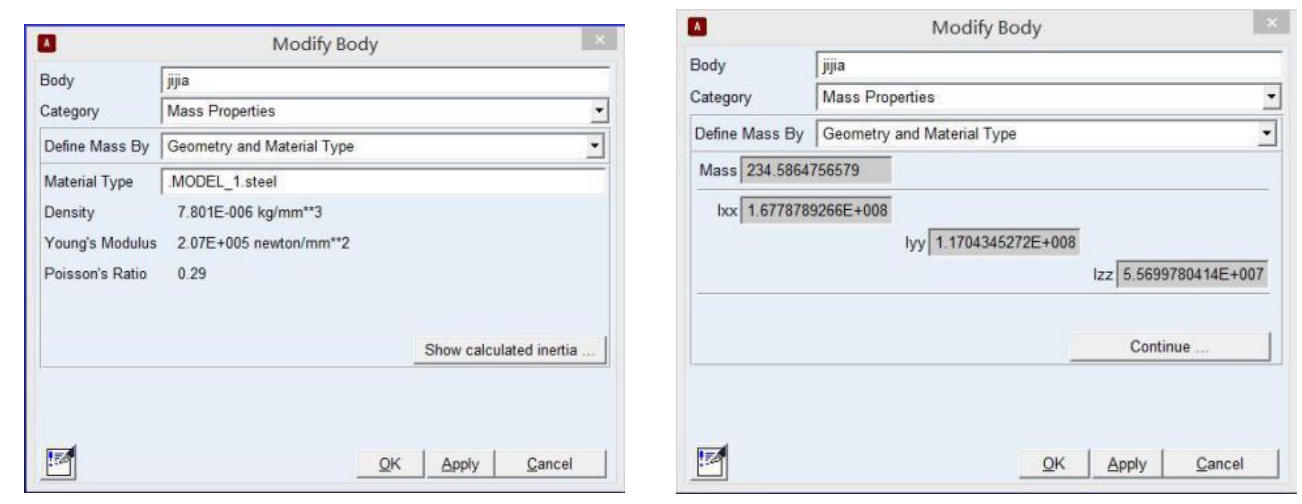

Fig.6 ADAMS set quality attributes

\subsubsection{Add motion driver function}

According to the previous theoretical analysis, the lifting mechanism is mainly driven by the extension and retraction of the piston rod of the hydraulic cylinder, and then the driving of the hydraulic cylinder is applied. This paper uses the step function form (STEP function) [19], the function format is: STEP (A, $\left.x_{0}, h_{0}, x_{1}, h_{1}\right)$.

In the formula: A--function arguments, generally as a function of time or time as an independent variable;

$x_{0}--$ the initial value of the function argument; 
$x_{1}$--the final value of the function argument;

$h_{0}$-- the initial value of the function;

$h_{1}$-- the final value of the function;

The right rear hydraulic cylinder applies the drive MOTION-1: STEP (time, 0, 0, 10, -100) + STEP (time, 15, 0, 20, $-50)+\operatorname{STEP}($ time, 25, 0, 30, 150);

The right front hydraulic cylinder applies the drive MOTION-2: STEP (time, 10, 0, 15, 50) + STEP (time, 20, 0, 25, 50);

That is, the left and right front hydraulic cylinders in 0S 10S have no action, the left and right rear hydraulic cylinders are extended $100 \mathrm{~mm}$ synchronously; the left and right rear hydraulic cylinders in 10S 15S have no action; the left and right front hydraulic cylinders are extended 50mm synchronously; 15S 20S inner and right front hydraulic cylinders have no action; left and right rear hydraulic cylinders extend $50 \mathrm{~mm}$ synchronously; 20S 25S inner left and right rear hydraulic cylinders have no action; left and right front hydraulic cylinders retract 50mm synchronously; 25S 30S inner left and right front The hydraulic cylinder has no action; the left and right rear hydraulic cylinders are retracted $150 \mathrm{~mm}$ synchronously. The displacement of each cylinder shown in Figure 7, where JOINT-17 is the displacement of the piston rod of the rear hydraulic cylinder, and JOINT-26 is the displacement of the piston rod of the front hydraulic cylinder.

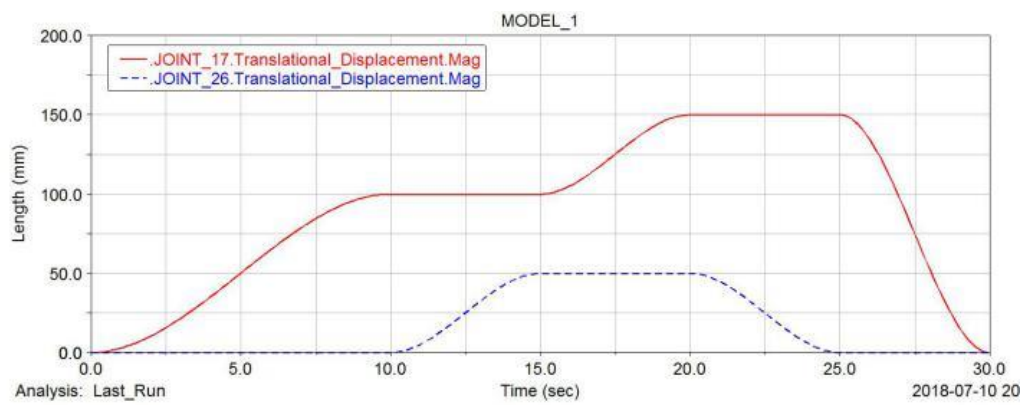

Fig.7 Hydraulic cylinder motion parameter

\subsection{Kinematics simulation analysis}

The exercise credit for the chassis is actually to analyze the angle change of the frame on the chassis relative to the ground during the movement of the lifting mechanism, and the analysis of the angular velocity, linear velocity and linear acceleration of each lifting element.

The tilt angle of the chassis frame can be calculated by the coordinates of each point on the chassis, as shown in Figure 8.

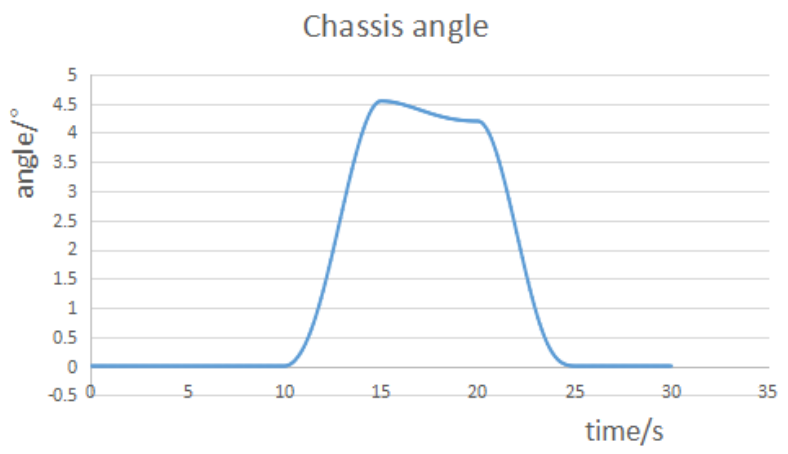


Fig.8 Tilt angle change

When the inclination angle of the chassis is $0 \mathrm{~S} \sim 10 \mathrm{~S}$, the inclination angle is zero, the front and rear lifting mechanisms are parallel, and the angular velocity is the same, and the chassis as a whole rises. At 10S 15S, the chassis angle sharply increased due to the extension of the front hydraulic cylinder, reaching 4.54 degrees at the 20th SS. At 15S 20S, the rear hydraulic cylinder continues to stretch. Due to the angle between the front and rear lifting mechanisms, the chassis inclination is slowly reduced, and it is reduced to 4.19 degrees in 20S. When 20S 25S, the front hydraulic cylinder is retracted to the initial position, and the chassis returns to the horizontal position at a high position. 25S 30S, the rear hydraulic cylinder is retracted to the initial position, the entire chassis is restored to the lowest position, and the lifting process ends. The chassis attitude is about 5 seconds from the horizontal straight tilt angle.

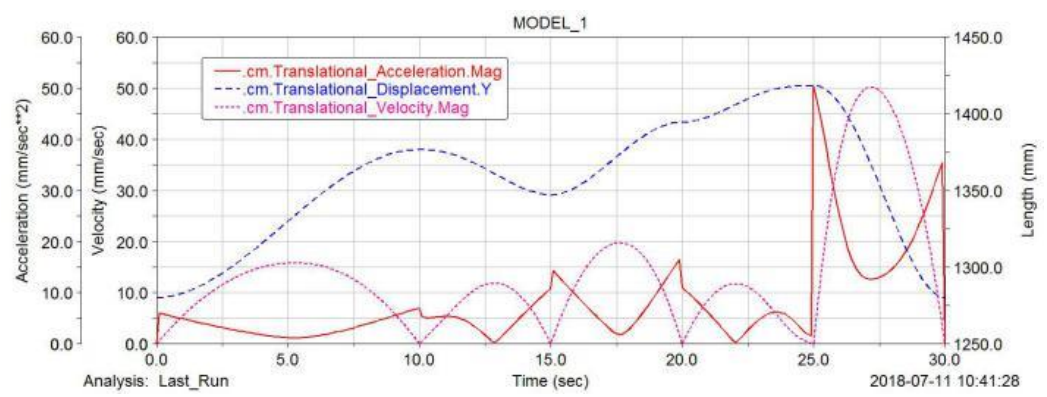

Fig.9 Chassis rack centroid height curve

In Figure 9, the center height of the chassis frame is $1280 \mathrm{~mm}$ from the initial value, reaching a maximum of $1418 \mathrm{~mm}$ at $25 \mathrm{~S}$, and then quickly drops to the lowest position. The center of mass increased by $138 \mathrm{~mm}$. The acceleration of the centroid can be seen as the magnitude of the impact it receives, reaching a maximum of $50 \mathrm{~mm} / \mathrm{s}^{2}$ at $25 \mathrm{~S}$. When actually driving the hydraulic cylinder, care should be taken to reduce the starting speed of the hydraulic cylinder to avoid large impact loads on the chassis frame.

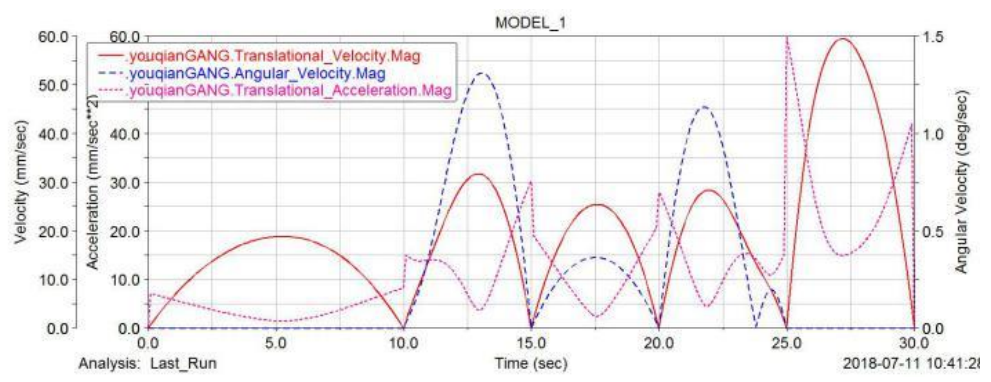

Fig.10 Right front upper arm hinge point speed and acceleration and angular curve

The curve of the speed, acceleration and angular velocity of the hinge point and the hydraulic cylinder of the right front lifting mechanism is shown in Fig. 10. The front upper arm is hinged to the front hydraulic cylinder, and the hinge point speed is the front cylinder speed curve. This exercise simulates the symmetrical movement of the left and right side lifting mechanisms, and the left front and right front mechanism speeds are consistent. The speed reached $59.38 \mathrm{~mm} / \mathrm{s}$ at $27.1 \mathrm{~s}$ is the maximum. The angular velocity is consistent with the change trend of the point velocity. It can be seen that the angular velocity values are small in the two periods of $0 \mathrm{~S} \sim 10 \mathrm{~S}$ and $15 \mathrm{~S} \sim 20 \mathrm{~S}$. At $27.1 \mathrm{~S}$ there is a maximum of $14.38^{\circ} / \mathrm{s}$. It can be seen from the acceleration curve that the instantaneous acceleration of the mechanism reaches $59.79 \mathrm{~mm} / \mathrm{s}^{2}$ at $25 \mathrm{~S}$ during the motion. 


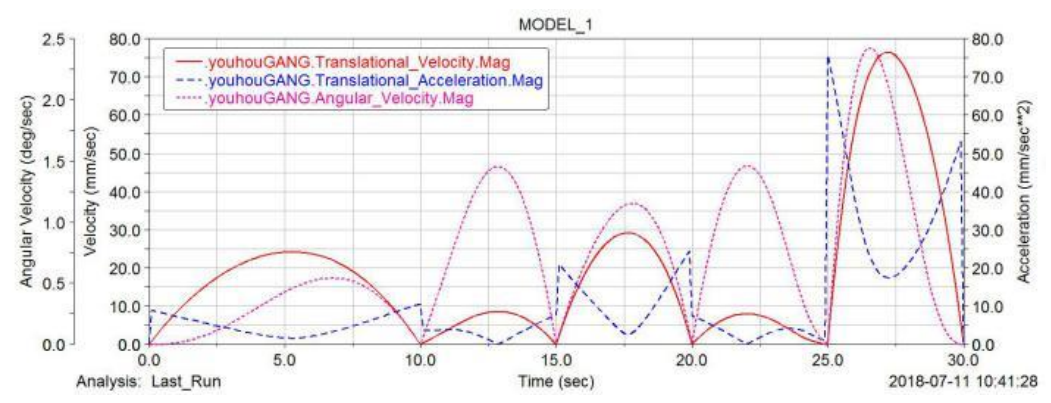

Fig.11 Right rear upper arm hinge point speed and acceleration and angular curve

The curve of the speed, acceleration and angular velocity of the hinge point and the hydraulic cylinder of the right rear lifting mechanism is shown in Fig. 11. The rear upper arm is hinged to the rear hydraulic cylinder, and the hinge point speed is the rear cylinder speed curve. This exercise simulates the symmetrical movement of the left and right side lifting mechanisms. The maximum speed of $75.16 \mathrm{~mm} / \mathrm{s}$ at $27.1 \mathrm{~S}$ is the maximum. The angular velocity is consistent with the change of the point velocity. It can be seen that the angular velocity values are small in the two periods of $10 \mathrm{~S} \sim 15 \mathrm{~S}$ and $20 \mathrm{~S} 25 \mathrm{~S}$. At $27.1 \mathrm{~S}$ there is a maximum of $14.38^{\circ} / \mathrm{s}$. It can be seen from the acceleration curve that the instantaneous acceleration of the mechanism reaches 75.67 $\mathrm{mm} / \mathrm{s}^{2}$ at $25 \mathrm{~S}$ during the motion.

\section{Conclusions}

In this paper, a crawler-type undercarriage device which could adjust the ground clearance was proposed. Through the theoretical calculation and computer simulation analysis, the variation curves of the chassis inclination angle during the adjustment process were obtained. And the ultimate attitude of the chassis and the maximum velocity and acceleration of the lifting mechanism were obtained. The conclusions are as follows:

(1) The front and rear adjustment tilt angle range could reach plus or minus 5 degrees, the overall lifting height was $14 \mathrm{~cm}$, and the range of the left and right lateral height difference could be adjusted to be $14 \mathrm{~cm}$;

(2) In the process of lifting adjustment, the maximum speed of the joint point between hydraulic cylinder and the hinge was $71.56 \mathrm{~mm} / \mathrm{s}$, and the maximum acceleration was $75.67 / \mathrm{s}^{2}$. The maximum angular velocity of the boom of the lifting mechanism was $14.38^{\circ}$ s. The maximum acceleration of the chassis centroid motion was $50 \mathrm{~mm} / \mathrm{s}^{2}$. It would not take more than 10 seconds to completely raise, and the leveling time would not exceed 5 seconds.

\section{ACKNOWLEDGEMENTS}

Jing Bo are very grateful to the financial support by the "13th Five-Year" National Key R\&D Program (2016YFD0702101), Jiangsu Distinguished Professor, Jiangsu Province "333 High-level Talent Cultivation Project", Jiangsu University Advantage Discipline Construction Project Funding Project (PDPA).

\section{References}

1. Cui Siyuan, Cao Guangqiao. Research on Combination of Agricultural Machinery and Agronomy in Main Rice Producing Areas of China [J]. Journal of Agricultural Mechanization on Research, 2014(05): 248-252.

2. Gao Huanwen, Li Hongwen, Li Wenying. Prospects of China Agricultural Mechanization Facing the 21st Century[J]. Transactions of the Chinese Society of Agricultural Engineering (Transactions of the CSAE), 2000(02): 9-12. 
3. Huang Ziqi. Talking about the promotion and use of harvesting machinery in hilly and mountainous areas[J]. China Southern Agricultural Machinery, 2001, (3): 7-8.

4. LUAN Feng. Study on the Selection of Combine Harvester for High Wet Rice Plots[J]. Agricultural Science \& Technology and Equipment, 2014, (9): 28-32.

5. Shi Xin. Study on the Leveling System of the Body in a Self-propelled Corn Combine Harvester[D]. Chang Chun: Jilin University, 2017.

6. Newlin E L. Work platform lift machine with scissor lift mechanism employing telescopeble electromechanical based lift actuation arrangement: US, US 6044927 A[P]. 2000.

7. Heckert G, Pfleghaar K. SCISSORS-TYPE ELEVATING PLATFORM: WO,WO/2005/058742[P]. 2005.

8. Rémi Figueredo, Pascal Sansen. KINEMATICS OPTIMIZATION OF A MECHANICALSCISSOR SYSTEM OF TIPPING USING A GENETIC ALGORITHM[J]. Mechanics Based Design of Structures and Machines, 42: 255266, 2014

9. WANG Xiao-long, XIE Fang-ping,LIU Da-wei. Design and experiment for the leveling device of the orchard lifting platform[J]. Journal of Hunan Agricultural University (Natural Sciences), 2014, 40(5): 548-551.

10. LIU Pingyi, GAO Jincheng, LI Haitao, et al. Terramechanics of all terrain adaptive locomotion chassis for farmland[J]. Transactions of the Chinese Society for Agricultural Machinery, 2012,43(10): 36-40.

11. WANG Ya, ChEN Sizhong, LI Haitao, et al. Design and experiment of high performance profiling terrain chassis with power train [J]. Transactions of the CSAE, 2012,28(Supp.1): 39-44.

12. Zhao Jianzhu, Wang Fengchen, Yu Bin, et al. Research on All-terrain Profiling Crawler Power Chassis [J]. Transactions of the Chinese Society for Agricultural Machinery, 2014,45(9): 20-24.

13. LV Guang-ming, LIU Ming-si, YANG Yang, et al. Dynamics simulation analysis on the working device of hydraulic excavator based on Pro/E_ADAMS[J]. Construction Machiner, 2013, (17): 86-90.

14. GUO Xiao-ning, ZENG Bin-bin. ADAMS-based virtual prototyping for excavators[J]. Chinese Journal of Construction Machinery, 2012, (04): 439-445.

15. Imanishi, Etsujiro, Nanjo, et al. Dynamic simulation of flexible multibody system with the hydraulic drive[J]. NipponKikai Gakkai Ronbunshu C,2003,69(9):2336-2343.

16. Bai Shixian. Advanced Kinematics and Dynamics of Mechanisms [M]. Shanghai science and Technology Press, 1988:1-3.

17. GUO Yongyao, LIU Li, SONG Zhilin. ADAMS/view Application of Conforming Key Parameters in Hydraulic Fork Lifting Platform [J].Equipment Manufacturing Technology, 2006,(6):38-40.

18. Song Shaoyun, Yin Fang. Application of ADAMS in mechanical design [M]. Beijing: National Defend Industry Press, 2017.

19. Li Zenggang. Detailed introduction and examples of ADAMS entry [J]. Beijing: National Defend Industry Press, 2014. 


\begin{tabular}{|l|l|l|}
\hline Authors & \multicolumn{1}{|c|}{ Name } & \multicolumn{1}{|c|}{ Biography } \\
\hline $1^{\text {st }}$ Author & Jing Bo & $\begin{array}{l}\text { (1993), male, master student, } \\
\text { mainly engaged in the joint } \\
\text { harvester crawler chassis } \\
\text { research. } \\
\text { Email: } \\
\text { jb18851401901@163.com }\end{array}$ \\
\hline $2^{\text {nd }}$ Author & Xu Lizhang & $\begin{array}{l}\text { (1993), male, Jiangsu Suqian, } \\
\text { Research Professor, mainly } \\
\text { engaged in mechanical basic } \\
\text { theory and key technology of } \\
\text { intelligent harvesting. } \\
\text { Email: justxlz@ujs.edu.cn }\end{array}$ \\
\hline
\end{tabular}

